\title{
A Resource-Based Perspective on China Hospital Alliance
}

\section{Liya Wang}

The School of Public Affairs, University of Science and Technology of China, Hefei, China

Email: liyawang1013@qq.com

How to cite this paper: Wang, L.Y. (2017) A Resource-Based Perspective on China Hospital Alliance. Open Journal of Social Sciences, 5, 289-294.

https://doi.org/10.4236/jss.2017.58024

Received: July 15, 2017

Accepted: August 27, 2017

Published: August 30, 2017

Copyright $\odot 2017$ by author and Scientific Research Publishing Inc.

This work is licensed under the Creative

Commons Attribution International

License (CC BY 4.0).

http://creativecommons.org/licenses/by/4.0/

\begin{abstract}
Recently in China, Hospital Alliance is considered to be the most effective solution of healthcare system. The purpose of research is to illustrate the concept of hospital alliance in China, use empirical research methodology of case study based on resource-based view. The main results get from the empirical analysis is to apply the modern theory of resource allocation and reallocation to redesign the model of hospital alliance, thus improve the quality of medical service and effectiveness. The final conclusion is to show a model of health delivery in China using pre-paid medical insurance.
\end{abstract}

\section{Keywords}

Hospital Alliance, Healthcare System, Resource-Based View

\section{Introduction}

\subsection{Research Background}

Recently in China, Hospital Alliance is considered to be the most effective solution of healthcare system. Chinese government emphasizes its importance of carrying out the hospital alliance. China's State Council issued the Guidance of the construction and development of promoting the hospital alliance to guide the solution nationwide. Premier Li Keqiang presided over the executive meeting of the State Council, deployed to promote the construction of hospital alliance. The mode of Hospital Alliance is the measure of deepening the reform of medical and medical insurance, rational allocation of resources and enabling people to enjoy high quality and convenient medical services.

\subsection{Theory}

Like any service system, healthcare can be considered to be the allocation or reallocation of three essential resources-people, processes and products [1]. 
Thus, a healthcare system is an integrated system of people, processes and products. It is of its essence to enhance its efficiency (leading to greater connection) and effectiveness (leading to improved health). Integration occurs over the individual, organizational and environmental dimensions [2]. In sum, the health care service systems are complicated, because of the ambiguityrelated to the nature of people-centered [3]. What's more, the solution of the system is to enhance integration and adaptation of the system.

\subsection{Significance}

Promoting the construction of hospital alliance has three important practical significant meanings, mainly listed as follows.

First, it embodies the health concept of people-centered. It does not only strengthen the construction and development of hospital alliance structures, but also strengthen the ability of health care gatekeepers for residents of basic medical and health institutions, so as to facilitate the people to seek medical treatment just in the neighborhood. At the same time, it promotes the convergence of medical treatment and prevention, health care, chronic disease prevention and treatment, which is the combination of management, health and pension services combined, it also can promote the transformation of health and healthy development from treatment-centered to health-centered, gradually realize to provide all-round, full cycle health services for the people of the target.

Second, it is in line with the development trend of China's medical service delivery system. Through the construction and development of hospital alliance, it fully plays a leading leading role within the three regional public hospitals, guiding the different levels and different types of medical institutions to establish clear objectives, clear responsibilities of the division of labor relations, promoting high-quality medical resources sinking, thus it can gradually solve the problem of the existing medical service system.

Third, it is conducive to high-quality medical resources sharing and integrating. It promotes the county hospital comprehensive capacity, and strengthening community health services, township hospitals and village clinics and other infrastructure construction, making basic medical and health institutions of the "hardware" was significantly improved at the same time.

\subsection{Structure}

The structure of this paper is first introduce the concept of the hospital alliance including the definition and the forms, and using the method of case study to illustrate the successful and innovative forms of hospital alliance, and show the achievement till now, including the conclusion and the implication of the paper.

\section{Concept of Hospital Alliance}

\subsection{Description of Hospital Alliance}

Hospital Alliance refers to a management system, which lies in a certain area, 
with high levels of medical institutions as the leading hospital, downward extends to the bottom of the integration of several low level medical institutions [4]. It shows in fan distribution, becoming a Hospital Alliance management system [5]. It is under the overall guidance of the government, more than a set of Hospital Alliance with coverage of a certain area residents, forming the connection between the upper and lower medical institutions. There are a variety of Hospital Alliance cooperation, of which three most representatives are listed as follows: first, closely connected with the link by shares; second, weak closely connected with the link by technology; third, the loose connection on patients referral based.

Hospital Alliance integrates the medical resources in the same area, with the aim of solving the issue of doctors' accessibility and availability. Through the optimal allocation of medical resources, thus to achieve hierarchical diagnosis and treatment, orderly medical treatment, improve the efficiency of the use of highquality medical resources, improve the level of primary medical care.

To achieve the nearest medical treatment, the patient's health services at the gate of the community center will be able to enjoy the same inspection service as the large hospital. To achieve convenient medical treatment, the establishment of referral green channel, primary referral patients provided priority care, priority examination, priority hospitalization and other services by the higher level hospitals. People get a comprehensive service from family physician, especially on the disease of hypertension and diabetes. So that doctors can not only "cure disease", but also "manage health". To save medical expenses, thus the hospital alliance implements medical insurance prepaid packages. The original revenue of medical institutions turn to be the cost, in this way, it can guide medical institutions to take the initiative to control unreasonable costs.

\subsection{Forms of Hospital Alliance}

At the city level, it is represented as medical groups. It is a management model which led by the municipal three level public hospital, the community health institutions, nursing homes, professional rehabilitation institutions, and so on, form a resource sharing, division of labor and coordination. Shenzhen Luohu medical group as the representative of the city level in the hospital alliance mode, within the alliance by sharing the people, fiance and assets, through the integration of the jurisdiction of public hospitals, organizing a hospital group, mutual recognition of testing results, overall planning of the funds, strengthen the development of the hospital specialized projects, to maximize resource sharing. Through the establishment of the board of directors and the board of supervisors, a modern hospital management system will be established to realize the separation of administration and management. The group consists of 6 district level hospitals, 35 community health centers, 9 resource management centers (inspection, image diagnosis, financial management, etc.) (see Figure $1)$. 


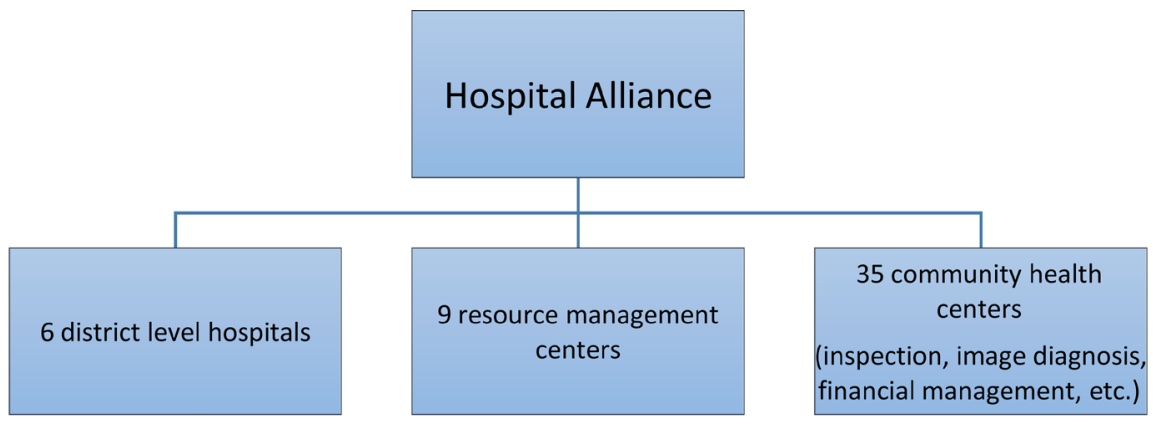

Figure 1. Shenzhen Luohu medical group chart.

\subsection{Current Situation of Hospital Alliance}

From the perspective of administration, hospital alliance system has been set up in every province in China. The state council issue a guidance on hospital alliance in April, 2017. On average, one big hospital will be connected several community health centers. Most of the hospital adopt the forms of sending experts to community or grass-root health centers in a certain period of time. The experts treat the patients in the community or give lectures about health management.

\subsection{Innovation of Hospital Alliance}

In order to make full use of the good human resources in the hospital alliance, Anhui health department initiates the attempt of senior nurses transfer to community health centers. Senior nurses usually refer to the clinical nurses over the age of 40, with 20 - 35 years of nursing experiences, rich in clinical experience, with certain management ability and strong legal awareness. The advantages of this attempt are listed as follows.

First, senior nurses play a key role in linking up the hospital alliance. Senior nurses from large hospitals working as the link of community health service centers and hospitals, utilizing their social network and other resources obtained from large hospitals, timely and accurately assist patients in community health centers in triage, referral to a hospital specialist departments and corresponding to the most appropriate experts to solve the tough problems. Residents can inquiries to the senior nurses in community, and also can be linked to experts in large hospitals by the senior nurse. It is convenient for residents get access to medical treatment, improving the credibility and compliance of the residents of the community, thus gradually developing the habit of the residents to approach the first treatment in the community hospital. It will definitely contribute a lot to the promotion of tiered medical service, improving the medical treatment of patients finally. Hypertension, diabetes, common cold, upper respiratory tract infection, acute and chronic gastroenteritis are the top five most common diseases among city residents. These diseases can be treated in the community by senior nurses to assist community doctors to carry out special treatment, and seriously ill patients are referral to the large hospital in hospital alliance. 
Second, senior nurses play the role of providing high-quality management resources to the community health centers. They will promote the standardized nursing practice as well as the standardized hospital management concept into the community health service centers. Thus it will improve medical service and the core competence of community medical staff. At present, there is no unified training for nurses, and there is a certain gap between community nurses' nursing practices and the standard practice of specialized nurses in large hospitals. The senior nurses can guide the community to improve the service quality as well as the service efficiency according to the standard management of large hospitals. Senior nurses transferred patients from community to large hospitals have more obvious advantages and practical significance than doctors working in the community. It achieves the optimal allocation of human resources of quality health care.

\section{Achievement}

Since the deepening of medical reform, Chinese government actively explored and carried out the construction of Hospital Alliance in accordance with local conditions. By the end of 2016, more than 205 cities at or above the prefecture level had been carrying out the reforms, accounting for more than $60 \%$, and initial achievements were made in the construction of hospital alliance.

The hardware and software at the grassroots level have been further improved, and the flow of patients has been changing gradually.

First, the flow of medical treatment has been changed gradually. In 2016, nearly ten million cases were transferred to big hospitals, with an increase of $62 \%$, meanwhile up to $2,600,000$ cases were transferred to the community health centers, with an increase of $117 \%$.

Second, within the hospital alliances, they provide experts, technical support, personnel training and facilities to support, thus the hardware and software in the community have been improved a lot.

Third, in terms of clinical technology, medical examination, pathological diagnosis, medical imaging diagnosis, hemodialysis and disinfection supply, etc., it has been achieved internal resource sharing, service homogeneity within the hospital alliance. By the scale and multiplier effect, the level of diagnosis and treatment is improved and medical expenses are reduced.

Fourth, with the improvement of finance, price, medical insurance and other supporting policies, an initial mechanism between the upper and lower levels has been formed, and thus promoting the construction of an integrated medical service delivery system.

\section{Conclusion}

The hospital alliance is relative new concept of health delivery in China. In accordance with the development of health delivery, hospital alliance is shown to be a reallocation of the resource in the context of medical. In China, hospital al- 
liance will be spread out in an effective way. From the perspective of resource, the hospital alliance will reunified the human resource, finance, assets and so on, to reallocation in an efficient way. In Anhui, the health government explores the innovative form and it is shown may be one of the ways of how to function the hospital alliance.

\section{Limitation}

The concept of hospital alliance gained achievements in some certain areas, as illustrated before, it is relatively successful in Luohu in Shenzhen City, south of China. However, the new model although very accessible, the model cannot spread out in whole China. Luohu district using medical insurance to contain the cost of medical fees. In China, the medical insurance system is too complex. In short time, it is not realistic to using the model of Luohu's medical insurance system. In terms of medical insurance, a lot of research can be done. Second implication is, the system of human resource management. For the community and the hospital, the HR management system is different. On the perspective of HR, often researches will be move on. Thirdly, the price of medical service should be considered, specifically family health delivery in community.

\section{References}

[1] O’Neill, C., Lamb, B. and Archbold, S. (2016) Cost Implications for Changing Candidacy or Access to Service within a Publicly Funded Healthcare System? Cochlear Implants International, 17, 31. https://doi.org/10.1080/14670100.2016.1161123

[2] Comite, U. (2011) The Managerial Perspective and System of Accountability in Italian Public Administration Observations on the Measurement of Effectiveness and Efficiency. International Academy of Business and Economics, 11.

[3] Kosny, A., Maceachen, E., Ferrier, S. and Chambers, L. (2011) The Role of Health Care Providers in Long Term and Complicated Workers' Compensation Claims. Journal of Occupational Rehabilitation, 21, 582. https://doi.org/10.1007/s10926-011-9307-3

[4] Lovell, C., Mandondo, A., Moriarty, P., Campbell, B.M. and Sayer, J.A. (2001) The Question of Scale in Integrated Natural Resource Management. Ecology \& Society, 5, 213-218.

[5] Zinn, J.S., Proenca, J. and Rosko, M.D. (1997) Organizational and Environmental Factors in Hospital Alliance Membership and Contract Management: A Resource-Dependence Perspective. Hospital \& Health Services Administration, 42, 67. 
Submit or recommend next manuscript to SCIRP and we will provide best service for you:

Accepting pre-submission inquiries through Email, Facebook, LinkedIn, Twitter, etc. A wide selection of journals (inclusive of 9 subjects, more than 200 journals)

Providing 24-hour high-quality service

User-friendly online submission system

Fair and swift peer-review system

Efficient typesetting and proofreading procedure

Display of the result of downloads and visits, as well as the number of cited articles Maximum dissemination of your research work

Submit your manuscript at: http://papersubmission.scirp.org/

Or contact jss@scirp.org 